\title{
Domácias e seu papel na defesa das plantas
}

\author{
Domatia mediating plant defense \\ Cláudia Helena Cysneiros Matos ${ }^{1}$ Angelo Pallini' $^{2}$ Luiz Luciano Bellini ${ }^{2}$ \\ Rita Cristina Pereira de Freitas ${ }^{3}$
}

\section{- REVISÃO BIBLIOGRÁFICA -}

\section{RESUMO}

Domácias são pequenas estruturas presentes na face inferior das folhas de diversas plantas de importância agrícola e têm sido descritas por serem tipicamente habitadas por ácaros (predadores e fungívoros) que provêm benefícios às plantas. São estruturas extremamente complexas e não apresentam qualquer função fisiológica conhecida. Tem sido postulado que os ácaros se beneficiam das domácias pela obtenção de um local seguro para reprodução e proteção contra predadores e que as plantas também se beneficiam pela redução do ataque de herbívoros ou patógenos. Assim, ecologistas têm hipotetizado que as domácias mediam uma associação mutualística entre as plantas e os ácaros que protegem as folhas. Nesta revisão, é discutido o papel das domácias na defesa das plantas contra pequenos artrópodes.

Palavras-chave: interação tritrófica, ácaro, mutualismo, defesa constitutiva, estruturas da folha.

\section{ABSTRACT}

Leaf domatia are small structures found on the underside of the leaves of many plants of agricultural importance. Domatia have been described to be typically inhabited by mites (predators and fungivorous) that provide benefits to the plant. The structures can be extremely complex and seem to have an unknown physiological function. It has been postulated that mites may get some benefit from leaf domatia by securing a safe place for reproduction and refuge from predators. Additionally, plants get benefits via reduced herbivory or pathogen attack. Hence, ecologists have hypothesized that domatia mediate a mutualistic association between plants and their bodyguard mites. In this review we discussed the pivotal role of the domatia in plant defenses against small arthropods.

Key words: tritrophic interaction, mite, mutualism, constitutive defense, leaf structures.

\section{INTRODUÇÃO}

As plantas se defendem do ataque de herbívoros através de mecanismos químicos e físicos, que podem afetar diretamente o desempenho dos herbívoros (defesa direta) ou auxiliar no recrutamento de inimigos naturais desses herbívoros (defesa indireta) (DICKE, 1999a;ARAGÃO et al., 2000; GOLS et al., 2003).

A utilização de mecanismos de defesa indireta pelas plantas ocorre comumente na natureza e representa um componente importante da dinâmica populacional em muitas comunidades (PRICE, 1986). Este tipo de defesa age sobre os herbívoros por promover a efetividade do terceiro nível trófico, ou seja, dos seus inimigos naturais (DICKE, 1999a). A ação desses mecanismos sobre os inimigos naturais pode se dar através da liberação de compostos voláteis, que os atraem para as plantas (MARGOLIES et al., 1997;

\footnotetext{
${ }^{1}$ Departamento de Biologia Animal/Entomologia, Universidade Federal de Viçosa (UFV), 36570-000, Viçosa, MG, Brasil. E-mail: chelena@insecta.ufv.br. Autor para correspondência.

${ }^{2}$ Departamento de Biologia Animal/Entomologia, UFV, Viçosa, MG, Brasil.

${ }^{3}$ Curso de Engenharia Agronômica, Viçosa, MG, Brasil.
} 
DICKE et al., 1998; PALLINI, 1998), ou pela presença de estruturas morfológicas nas plantas que favoreçam sua presença e manutenção (MARQUIS \& WHELAN, 1996; WALTER, 1996; MATOS et al., 2004).

A proteção de plantas por inimigos naturais é bem documentada na literatura, sendo, em alguns casos, tão notável que os inimigos naturais são referidos como "guarda-costas" das plantas (DICKE \& SABELIS, 1988; WHITMAN, 1994). É importante ressaltar que plantas e inimigos naturais de seus herbívoros interagem de diferentes formas e que muitas destas interações não favorecem apenas os inimigos naturais, mas podem levar ao benefício de ambos (SABELIS et al., 1999). Isso não ocorre ao acaso, já que, no decorrer da evolução, estas interações podem ter surgido como fator fundamental para a sobrevivência das espécies (EDWARDS \& WRATTEN, 1981).

Estudos têm revelado interações substanciais entre características morfológicas das plantas (ex: tricomas, pilosidade e domácias) e os agentes de controle biológico (MESSINA \& HANKS, 1998; DICKE, 1999b), que podem influenciar a habilidade desses organismos em suprimir populações de herbívoros (MICHALSKA, 2003). Tais características podem agir positivamente ou negativamente sobre os inimigos naturais, fazendo com que algumas espécies tenham preferência por residir em hábitats com determinadas características do que com outras.

No caso específico das domácias, diversas pesquisas vêm sendo desenvolvidas com o intuito de se obter informações sobre essas estruturas e sua influência nas interações entre as plantas e os inimigos naturais dos seus herbívoros. Essas estruturas vêm sendo consideradas como parte da defesa das plantas, pois até hoje não foi encontrada qualquer função fisiológica para elas (NAKAMURA et al., 1992). Além disso, essas estruturas têm se mantido ao longo do processo evolutivo e, de maneira geral, apresentam associações com inimigos naturais dos herbívoros que ocasionam danos às plantas (O'DOWD \& WILSON, 1989). Dessa forma, essa revisão tem o objetivo de apresentar os principais estudos desenvolvidos sobre a interação entre plantas com domácias e ácaros e suas possíveis implicações no controle biológico de ácarospraga.

Principais considerações sobre domácias

Domácias são estruturas presentes nas folhas de diversas espécies de plantas, sendo encontradas sob a forma de tufos de pêlos ou cavidades (com ou sem pêlos) localizadas nas junções entre a nervura principal e as secundárias, na face abaxial das folhas. No geral, sua distribuição ocorre desde a base do limbo até aproximadamente 2/3 do comprimento da folha (BARROS, 1960). Essas estruturas ocorrem em plantas das regiões tropicais e temperadas, sendo predominantes em plantas das regiões tropical e subtropical úmidas (NAKAMURA et al., 1992; NORTON et al., 2000). São muito comuns dentre as dicotiledôneas e raras ou ausentes nas monocotiledôneas (O’DOWD \& WILSON, 1989). Além disso, variam em forma e número dentro e entre as espécies de plantas (BARROS, 1961a).

As primeiras observações sobre domácias foram feitas por GOELDI (1887) em folhas de cafeeiro, que as descreveu como pequenas saliências do tamanho de uma cabeça de alfinete, presentes em todos os pontos das ramificações das nervuras secundárias nas folhas. Mas o termo "domácia” foi utilizado pela primeira vez por LUNDSTRÖEM (1887) que, após estudar essas estruturas, observou que as mesmas serviam de refúgio e moradia para ácaros, dando-lhes a denominação de “domácias” (gr. domatium = casa pequena) ou acarodomácias. Essas estruturas foram interpretadas como "adaptações a uma simbiose mutualística entre a planta e os ácaros que ali vivem”, mas esta teoria foi logo abandonada pelos botânicos, que passaram a utilizar o termo domácia apenas para as estruturas presentes nas junções das nervuras das folhas.

Ao longo do tempo, as domácias tornaramse objeto de investigações detalhadas por parte dos pesquisadores, que lhes atribuíram valor morfológico e taxonômico (BARROS, 1961b). Porém, durante quase um século, as considerações sobre a relação entre essas estruturas e a presença de ácaros foram ignoradas ou ridicularizadas (O’DOWD \& WILSON, 1989).

O termo domácia também tem sido aplicado a vários tipos de cavidades presentes nas plantas e que são utilizadas por formigas como local de ninho (HUXLEY, 1986). Neste caso, tais estruturas são consideravelmente maiores do que aquelas habitadas por ácaros e ocorrem em outras partes da planta, como, por exemplo, no caule (BEATTIE, 1985). No entanto, quando se trata da associação entre ácaros e domácias, o termo “domácia” se refere apenas às domácias foliares.

A hipótese do mutualismo planta-predador e suas evidências

Nas últimas décadas, estudos têm demonstrado que domácias são realmente utilizadas por ácaros, predominantemente predadores e fungívoros (O’DOWD \& WILSON, 1991; WALTER \& DENMARK, 1991; WALTER, 1996; WALTER \& O’DOWD, 1997; MATOS, 2001), retomando assim a 
hipótese de mutualismo sugerida por LUNDSTRÖEM (1887).

Dentre os principais ácaros que ocupam essas estruturas, destacam-se os predadores Phytoseiidae e Stigmaeidae e espécies fungívoras e / ou polenófagas de Tydeidae (família cujo hábito alimentar é bastante variado e discutido) (O’DOWD \& WILSON, 1989; PEMBERTON \& TURNER, 1989; O’DOWD, 1994). Ocasionalmente, ácaros herbívoros e pequenos insetos, como tripes e larvas de moscabranca, também são encontrados no interior das domácias, mas raramente são vistos em abundância (para exemplo de ocupação de domácias por ácaros fitófagos ou insetos, ver MOUND, 1993; KASAI et al., 2002; ROMERO \& BENSON, 2004).

Estudos têm demonstrado que ( $1^{\circ}$ ) plantas que possuem domácias apresentam significativamente mais ácaros predadores e fungívoros do que plantas que não possuem essas estruturas (WALTER \& O’DOWD, 1992a,b; O’DOWD \& PEMBERTON, 1998; ENGLISH-LOEB et al., 2002); e ainda que (2ํ) plantas com altas densidades de domácias têm mais ácaros predadores do que plantas com poucas domácias (MATOS, 2001). Entretanto, para que a hipótese de mutualismo sugerida por LUNDSTRÖEM (1887) seja comprovada, é preciso que sejam dadas evidências do benefício mútuo dessa associação.

Três critérios foram definidos por PEMBERTON \& TURNER (1989) como necessários para comprovar a interação mutualística entre plantas com domácias e ácaros: (1ํํa ácaros têm que utilizar as domácias; ( $2^{\circ}$ ) eles precisam se beneficiar desse uso e $\left(3^{\circ}\right)$ as plantas precisam se beneficiar do aumento da atividade dos ácaros devido às domácias. Assim, a principal vantagem para a planta seria a habilidade de adquirir "guarda-costas" (WHITMAN, 1994) para protegê-las dos herbívoros, enquanto o predador se beneficiaria do abrigo provido pelas domácias.

Há muitos exemplos da utilização de domácias por ácaros (PEMBERTON \& TURNER, 1989; WALTER \& DENMARK, 1991; AGRAWAL, 1997; NORTON et al., 2000; MATOS, 2001). Além disso, existem evidências de que ácaros se beneficiam ao utilizar domácias e de que essas estruturas afetam sua abundância, distribuição, reprodução e sobrevivência (NORTON et al., 2001).

Estudos têm demonstrado que a remoção artificial de domácias em algumas espécies de plantas afeta negativamente a abundância de ácaros potencialmente benéficos (fungívoros, polenófagos, predadores) (WALTER \& O'DOWD, 1992a; GROSTAL \& O’DOWD, 1994; ENGLISH-LOEB et al., 2002). A abundância de ácaros benéficos em folhas com domácias pode ser explicada por diversos fatores, tais como: maior disponibilidade de sítios de oviposição e de refúgio (contra condições abióticas adversas ou inimigos naturais), possibilitando assim maior fecundidade e/ou sobrevivência desses organismos, bem como maior permanência dos mesmos nas plantas. Na realidade, estudos têm demonstrado que domácias são responsáveis pelo aumento da reprodução de ácaros predadores em condições de baixa umidade (WALTER \& DENMARK, 1991; GROSTAL \& O'DOWD, 1994; O’DOWD\& PEMBERTON, 1998), que elas diminuem a predação intraguilda de ácaros predadores que habitam essas estruturas (RODA et al., 2000; NORTON et al., 2001), e que podem proporcionar maior sobrevivência a esses organismos (MATOS et al., 2004). Além disso, essas estruturas podem protegê-los de condições abióticas adversas na superfície das folhas (ROSARIO, 1995) e disponibilizar refúgios (AGRAWAL et al., 2000; RODA et al., 2000; NORTON et al., 2001), inclusive contra o ataque por inimigos naturais, como Chrysopidae (ROSARIO, 1995). Desta forma, são claros os benefícios das domácias para os ácaros benéficos, entretanto, quais os efeitos sobre os ácaros herbívoros e as plantas?

Poucos estudos têm demonstrado os efeitos das domácias sobre ácaros herbívoros. GROSTAL \& O’DOWD (1994) demonstraram que folhas com domácias favorecem um aumento significativo da taxa de predação de Neoseiulus occidentalis (Acari: Phytoseiidae) sobre Tetranychus urticae (Acari: Tetranychidae). AGRAWAL \& KARBAN (1997) adicionaram domácias artificiais a plantas de algodoeiro e observaram diminuição na densidade de herbívoros além do aumento na densidade de predadores e da produtividade destas plantas em relação ao controle (plantas sem adição de domácias). Entretanto, a adição artificial de domácias possibilitou à planta o benefício de possuí-las sem ter que investir na formação de suas estruturas, o que, desta forma, impediu a avaliação do quanto ela gasta na produção de domácias e qual é o benefício líquido que estas estruturas lhes proporcionam. Similarmente, NORTON et al. (2000) demonstraram que as domácias beneficiam a planta por aumentar a abundância de ácaros fungívoros, o que resulta no decréscimo do dano ocasionado por doenças. Estes resultados indicam que pode haver benefício para ambos, plantas e inimigos naturais, porém o efeito em valor adaptativo para as plantas ainda permanece pouco claro.

Diante do demonstrado, torna-se evidente que são muitos os resultados sugerindo a existência de mutualismo entre plantas com domácias e os ácaros que nelas se abrigam, porém ainda não há estudos que atendam aos três critérios propostos por PEMBERTON 
\& TURNER (1989), principalmente no que se refere ao efeito dessas estruturas no aumento do valor adaptativo das plantas.

Principais limitações para comprovação do mutualismo planta-predador

Conforme demonstrado, tem crescido consideravelmente nas últimas décadas o interesse em se testar a hipótese do mutualismo entre ácaros e plantas com domácias. Entretanto, apesar do avanço das pesquisas nessa área, há uma grande dificuldade em se estabelecer metodologias que consigam atender aos três critérios sugeridos por PEMBERTON \& TURNER (1989) e que, desta forma, comprovem esta hipótese. A principal limitação das metodologias utilizadas não está em conseguir mostrar os benefícios das domácias para as plantas, e sim em poder avaliar os custos envolvidos e suas conseqüências no que se refere ao valor adaptativo das mesmas.

A maioria dos estudos testa o efeito nas plantas através da remoção de domácias - no caso de domácias do tipo cavidade - tampando-se as estruturas com cola ou material similar. Já em domácias do tipo tufos de pêlos, promove-se a retirada dos pêlos ou impossibilita-se o acesso a essas estruturas pelos ácaros (WALTER \& O’DOWD, 1992 a, b; AGRAWAL, 1997). Alternativamente, outra forma de se testar o papel das domácias é pela adição de domácias artificiais geralmente utilizando-se tufos de algodão hidrófilo (AGRAWAL, 1997; AGRAWAL \& KARBAN, 1997). Entretanto, ao se adicionar domácias, a planta "ganha" essas estruturas sem ter um gasto energético na sua produção, não sendo possível avaliar, desta forma, o real benefício líquido que a adição de domácias lhes proporciona. Por outro lado, ao se eliminar domácias, ocorre o inverso, a planta "perde essas estruturas", conseqüentemente há uma redução no seu valor adaptativo, mas não há uma redução da energia utilizada na sua produção, uma vez que essas estruturas continuam a ser produzidas e só depois são retiradas. Isso demonstra que a elaboração de metodologias não é fácil e que só através do desenvolvimento de pesquisas é possível se ajustar as metodologias existentes até o momento ou se descobrir novas alternativas para se testar o mutualismo entre ácaros e plantas com domácias.

Experimentos devem ser planejados, por exemplo, de modo a se utilizar variedades de plantas que possuam diferentes densidades e tamanhos de domácias. O acesso a banco de germoplasmas pode permitir encontrar variedades que apresentem diferenças nesse atributo.

Foi observado que grupos próximos de plantas comerciais possuem quantidade e tamanho diferenciado de domácias, como é o caso de plantas de café como Coffea arabica - com muitas domácias desenvolvidas - e Coffea canephora - com poucas domácias incipientes (MATOS et al., 2005). Usando esse caso como exemplo, seria importante avaliar se há diferenças na densidade e no tipo de domácias em diferentes variedades de determinada espécie em particular - por exemplo, entre variedades de Coffea arabica - e comparar as densidades de ácaros-praga e predadores nessas plantas. $\mathrm{O}$ valor adaptativo das plantas deve ser avaliado medindo-se a sua produção (número de sementes). Como conseqüência, os resultados devem proporcionar estimativas dos custos e benefícios das domácias para as plantas, bem como indicar sua importância para o controle de pragas.

\section{CONCLUSÕES}

A associação entre plantas com domácias e ácaros é um exemplo de como as características da arquitetura da planta podem agir diretamente sobre o terceiro nível trófico (GROSTAL \& O’DOWD, 1994; WHITMAN, 1994). Entretanto, ao se avaliar diferentes espécies de plantas com domácias e a relação entre essas estruturas e os ácaros benéficos, não se pode deixar de levar em consideração que outros fatores, além dessas estruturas, podem influenciar a distribuição dos ácaros nas folhas, como: a disponibilidade e qualidade das presas (HLUCHY et al., 1991), aspectos químicos da folhas (DICKE \& SABELIS, 1988), e outros caracteres morfológicos como tricomas e pêlos (KREITER et al., 2002 ).

Diversas plantas de importância econômica possuem domácias, incluindo diferentes variedades de uva, café, algodão, abacate, pimenta, caju, dentre outras. Assim, estudos voltados para o entendimento das interações existentes entre ácaros benéficos e essas estruturas são de grande importância, uma vez que podem auxiliar em programas de controle de ácarospraga. A presença de domácias nas plantas pode contribuir para um melhor desempenho de ácaros predadores e fungívoros como agentes de controle biológico, uma vez que favorece a permanência desses organismos nas plantas, por lhes proporcionar abrigo, sítios de oviposição e maior sobrevivência.

\section{REFERÊNCIAS}

AGRAWAL, A.A. Do leaf domatia mediate a plant-mite mutualism? An experimental test of the effects on predators and herbivores. Ecological Entomology, v.22, n.4, p. 371376, 1997.

AGRAWAL, A.A.; KARBAN, R. Domatia mediate plantarthropod mutualism. Nature, v.387, n.6633, p.562-563, 1997. 
AGRAWAL, A.A, et al. How leaf domatia and induced plant resistance affect herbivores, natural enemies and plant performance. Oikos, v.89, n.1, p.70-80, 2000.

ARAGÃO, C.A. et al. Tricomas foliares associados à resistência ao ácaro rajado (Tetranychus urticae Koch.) em linhagens de tomateiro com alto teor de 2-tridecanona nos folíolos. Ciência \& Agrotecnologia, v.24 (edição especial), p.81-93, 2000.

BARROS, M.A.A. Morfologia e anatomia das domácias em Coffea arabica L. Anais da Escola Superior de Agricultura “Luiz de Queiroz”, v.17, p.165-206, 1960.

BARROS, M.A.A. Domácias nas Angiospermas: variações na forma e na localização. Anais da Escola Superior de Agricultura “Luiz de Queiroz”, v.18, p.131-146, 1961a.

BARROS, M.A.A. Ocorrência das domácias nas Angiospermas. Anais da Escola Superior de Agricultura "Luiz de Queiroz”, v.18, p.113-130, 1961 b.

BEATTIE, A.J. The evolutionary ecology of ant-plant mutualisms. Cambridge: Cambridge University, 1985. 182p.

DICKE, M. Evolution of induced indirect defense of plants. In: ELLIS, P.R; FREULER, J. Breeding for resistance to insects and mites. IOBC WPRS Bulletin, v.19, n.5, p.72-80, 1999a.

DICKE, M. Plant characteristics influence biological control agents: implications for breeding for host plant resistance. In: HARVELL, C.D.; TOLLRIAN, R. The ecology and evolution of inducible defenses. Princeton, NJ: Princeton University, 1999b. p.62-88.

DICKE, M.; SABELIS, M.W. How plants obtain predatory mites as bodyguards. Netherland Journal of Zoology, v.38, p.148-165, 1988.

DICKE, M. et al. Plant-phytoseiid interactions mediated by prey-induced plant volatiles: variation in production of cues and variation in responses of predatory mites. Experimental \& Applied Acarology, v.22, n.6, p.311-333, 1998.

EDWARDS, P.J.; WRATTEN, S.D. Ecologia das interações entre insetos e plantas. São Paulo: EPU, 1981. 71p.

ENGLISH-LOEB, G.M. et al. Behavioral and population consequences of acarodomatia in grapes on phytoseiid mites (Mesostigmata) and implications for plant breeding. Entomologia Experimentalis et Applicata, v.104, n.2-3, p.307-319, 2002.

GOELDI, E.A. Relatório sobre a moléstia do cafeeiro na província do Rio de Janeiro. Rio de Janeiro: Imprensa Nacional, 1887. 121p.

GOLS, R. et al. Induction of direct and indirect plant responses by jasmonic acid, low spider mite densities, or a combination of jasmonic acid treatment and spider mite infestation. Journal of Chemical Ecology, v.29, n.12, p.2651-2666, 2003.

GROSTAL, P.; O’DOWD, D.J. Plants, mites and mutualism: leaf domatia and the abundance and reproduction of mites on Viburnum tinus (Caprifoliacea). Oecologia, v.97, n.3, p.308315, 1994.
HLUCHY, M. et al. Phytophagous and predatory mites (Acari: Tetranychidae, Eriophyidae, Phytoseiidae, Stigmaeidae) in South Moravian vineyards, Czechoslovakia, treated with various types of chemicals. Experimental and Applied Acarology, v.13, n.1, p.41-52, 1991.

HUXLEY, C.R. Evolution of benevolent ant-plant relationships. In: JUNIPER, B.; SOUTHWOOD, R. Insects and the plant surface. London: Edward Arnold, 1986. p.257282 .

KASAI, A. et al. Density of the eriophyid mites inhabiting the domatia of Cinnamomum camphora Linn. affects the density of the predatory mite, Amblyseius sojaensis Ehara (Acari: Phytoseiidae), not inhabiting the domatia. Applied Entomology and Zoology, v.37, n.4, p.617-619, 2002.

KREITER, S. et al. Plant and leaf characteristics influencing the predaceous mite Kampimodromus aberrans (Acari: Phytoseiidae) in habitats surrounding Vineyards. Environmental Entomology, v.31, n.4, p.648-660, 2002.

LUNDSTRÖEM, A.N. Pflanzenbiologische studien II. Die Anpassungen der Pflanzenan Thiere. Domatienführende Pflanzen. In: MARIANI, M.J. Les caféiers. Paris: L' Université, 1887. p.1-88.

MARGOLIES, D.C. et al. Response of a phytoseiid predator to herbivore-induced plant volatiles: selection on attraction and effect on prey explotation. Journal of Insect Behavior, v.10, p.695-709, 1997.

MARQUIS, R.J.; WHELAN, C. Plant morphology and recruitment of third trophic level: subtle and little-recognized defenses? Oikos, v.75, n.2, p.330-334, 1996

MATOS, C.H.C. Domácias intermediando interações tritróficas em cafeeiros. 2001. 61f. Dissertação (Mestrado em Entomologia) - Curso de Pós-graduação em Entomologia, Universidade Federal de Viçosa.

MATOS, C.H.C. et al. Domácias do cafeeiro beneficiam o ácaro predador Iphiseiodes zuluagai Denmark \& Muma (Acari: Phytoseiidae)? Neotropical Entomology, v.33, n.1, p.5763, 2004.

MATOS, C.H.C. et al. Do domatia mediate mutualistic interactions between coffee plants and predatory mites? Entomologia Experimentalis et Applicata, 2005 (no prelo).

MESSINA, F.J; HANKS, J.B. Host plant alters the shape of the functional response of an aphid predator (Coleoptera: Coccinelidae). Environmental Entomology, v.27, n.5, p.1196-1202, 1998.

MICHALSKA, K. Climbing of leaf trichomes by eriophyid mites impedes their location by predators. Journal of Insect Behavior, v.16, n.6, p.833-844, 2003.

MOUND, L.A. The first thrips species (Insecta) inhabiting leaf domatia: Domatiathrips cunninghamii gen. et. sp. nov. (Thysanoptera: Phlaeothripidae). Journal of the New York Entomological Society, v.101, p.424-430, 1993.

NAKAMURA, T. et al. Leaf anatomy of Coffea arabica L. with reference to domatia. Japanese Journal of Crop Science, v.61, n.4, p.642-650, 1992. 
NORTON, A.P. et al. Mycophagous mite and foliar pathogens: leaf domatia mediate tritrophic interactions in grapes. Ecology, v.81, n.2, p.490-499, 2000.

NORTON, A.P. et al. Host plant manipulation of natural enemies: leaf domatia protect beneficial mites from insect predators. Oecologia, v.126, n.4, p.535-542, 2001.

O'DOWD, D.J. Mite association with the leaf domatia of coffee (Coffea arabica) in North Queensland, Australia. Bulletin of Entomological Research, v.84, p.361-366, 1994.

O’DOWD, D.J.; WILSON, M.F. Leaf domatia and mites on Australian plants: ecological and evolutionary implications. Biological Journal of the Linnean Society, v.37, p.191236, 1989.

O’DOWD, D.J.; WILSON, M.F. Associations between mites and leaf domatia. Trends in Ecology and Evolution, v.6, n.6, p.179-182, 1991.

O’DOWD, D.J.; PEMBERTON, R.W. Leaf domatia and foliar mite abundance in broadleaf deciduous forest of north Asia. American Journal of Botany, v.85, n.1, p.70-78, 1998.

PALLINI, A. Odour-mediated indirect interactions in an arthropod food web. 1998. 91f. Thesis (PhD in Population Biology) - University of Amsterdam.

PEMBERTON, R.W.; TURNER, C.E. Occurrence of predatory and fungivorous mites in leaf domatia. American Journal of Botany, v.76, n.1, p.105-112, 1989.

PRICE, P.W. Ecological aspects of host plant resistance and biological control: interactions among three trophic levels. In: BOETHEL, D.J.; EIKENBARY, R.D. Interactions of plant resistance and parasitoid and predators of insects. New York: Wiley, 1986. p.11-30.

ROMERO, G.Q.; BENSON, W.W. Leaf domatia mediate mutualism between mites and a tropical tree. Oecologia, v.140, n.4, p.609-616, 2004.
RODA, A.L. et al. Trichomes and spider mite webbing protect predatory mite eggs from intraguild predation. Oecologia, v.125, n.3, p.428-435, 2000.

ROSARIO, S.A. Association between mites and leaf domatia Evidence from Bangladesh, South-Asia. Journal of Tropical Ecology, v.11, p.99-108, 1995.

SABELIS, M.W. et al. The evolution of direct and indirect plant defence against herbivorous arthropods. In: OLFF, et al. Herbivores: between plants and predators. Oxford: Blackwell Science, 1999. p.109-166.

WALTER, D.E. Living on leaves: mites, tomenta, and leaf domatia. Annual Review of Entomology, v.41, p.101-114, 1996.

WALTER, D.E.; DENMARK, H.A. Use of leaf domatia on wild grape (Vitus munsoniana Simpson) by arthropods in central Florida. Florida Entomologist, v.74, n.3, p.440-446, 1991.

WALTER, D.E.; O’DOWD, D.J. Leaf morphology and predators: effect of leaf domatia on the abundance of predatory mites (Acari: Phytoseiidae). Environmental Entomology, v.21, n.3, p.478-484, 1992a.

WALTER, D.E.; O’DOWD, D.J. Leaf with domatia have more mites. Ecology, v.73, n.4, p.1514-1518, 1992b.

WALTER, D.E.; O'DOWD, D.J. The good, the bad, and the ugly: which really inhabit domatia? In: NEEDHAM et al. Acarology IX: symposia. Ohio: Ohio Biological Survey, 1997. p. 215-220.

WHITMAN, D.W. Plant bodyguards: mutualistic interactions between plants and the third trophic level. In: ANANTHAKRISHNAN, T.N. Functional dynamics of phytophagous insects. New Delhi: Oxford and IBH, 1994. p.133-159. 